\title{
Research on Digital Art Design Mode in China Based on 3D Animation Design Analysis
}

\author{
Yidong Liu*, Yiran Fan \\ School of Digital Media, Chongqing College of Electronic Engineering, Chongqing 401331, China \\ *Corresponding Author email: 47418946@qq.com
}

Keywords: 3D animation; digital art; design pattern

\begin{abstract}
Through in-depth observation and quantitative analysis of China's digital art, combined with the current development of computer graphics hardware and 3D animation technology, this paper carries out the research of 3D animation art technology based on programmable graphics hardware. The use of 3D animation technology to produce digital art, explores new technologies to achieve traditional animation methods, produce digital art, not only improve efficiency, but also make the animation of the performance space expand to three-dimensional space. With the help of 3D animation technology, digital art will keep pace with the times and present its own distinctive characteristics. Under the influence of 3D animation technology, digital art has undergone a new development. Combining traditional animation art with 3D animation technology, it has not only formed a new form of animation art expression, but also expanded a new field of creation for animation art. Corresponding to the aesthetics and market requirements of the digital age, it extracts the means and methods that combine the cultural essence of traditional digital art and the aesthetic characteristics of film and television with modern high technology, and finally form a new production mode such as the basic technology and creation program of 3D digital art.
\end{abstract}

\section{Introduction}

In 1995, Disney Film Company and Pixar Animation Studio jointly launched the first 3D animation film Toy Story. Since then, 3D digital technology has gradually been popularized in the design of film and television animation, becoming an indispensable technical support for film and television animation production [1]. On this basis, the shortcut is to draw on the formation of Japanese and American animation industry conditions, the formation process and the formation of magic weapon, to revitalize Chinese animation [2]. As a classic representative of Chinese traditional animation, 3D animation has witnessed the brilliance and Contemporary Dilemma of Chinese animation, and has returned to our vision again under the call of the magic of digital art. It is precisely because of the strong technical support of 3D digital technology that the animation art has a broader creative space [3-5]. Today's powerful 3D digital technology is not only the beginning of the development of the "computer special effects", its powerful "virtual technology" for the audience today's computer 3D technology is no longer a narrow "computer special effects", it can present a lot of reality can not show the scene [6]. It greatly enriches audio-visual language and brings new technological and artistic revolution to animation art [7]. No matter in the field of artistic animation creation or film and television column packaging, especially in the creation of digital 3D animation, there are few outstanding works, and there is no detailed summary of practice or academic review to study and summarize its artistic performance and production technology [8-10].

\section{The application of 3D digital technology in animation design and production}

3D animation has a good acceptance and universal adaptability because of its point-to-surface and profound artistic characteristics. It has a wide range of applications in animation advertising, TV column packaging, architectural landscape animation and so on. Any complete animation works, in 
addition to the design of novel role modeling, but also with the story, role matching animation scene. Scenes are all the backgrounds that accompany the plot development and character activities, including natural scenes, social environments, historical environments, and the character's place of life. The column packaging film of the CCTV Opera Channel and the new image commercial film launched by the CCTV Advertising Department have all adopted the 3D form for interpretation. Jiangnan has a rich cultural heritage and rich tourism resources. Many landscapes are especially suitable for use in 3D form, whether it is the romantic scene of the broken bridge and the cultural heritage of Qushui. The 3D animation promo is undoubtedly an excellent carrier for promoting urban culture and tourism resources, corresponding to the aesthetics and market requirements of the digital age. Combining the cultural essence of traditional Chinese 3D animation with modern high-tech means, the feasibility and universality of the research results of $3 \mathrm{D}$ animation art theory and production technology are high.

The film and television animation art is a dynamic visual art that shapes the character and promotes the development of the story through the movement of characters. As a gem of Chinese animation art, 3D animation has a unique Chinese national charm, and 3D cartoons bring Chinese traditional painting 3D painting into animation production. The combination of the flexibility of cartoons and the elegant and profound artistic conception of Chinese paintings has made a major breakthrough in the artistic style and spiritual realm of cartoons. The performance space of Chinese traditional 3D painting is reflected by the ink thickness. Generally speaking, the farther away, the lighter, the later 3D production can effectively solve this problem. Chinese traditional 3D paintings are exquisite, and the brushstrokes of different degrees of wetting and wetting show the texture of different objects. Movie and TV animation scene is a typical space environment for plot unfolding and character activities, is the main creative link of the formation of animation style. The animation scene design based on 3D digital technology has a completely different performance language from the two-dimensional animation. It breaks through the traditional animation line-based modeling, but to simulate the real light and shadow space as the main modeling elements.

\section{Research on the creation of digital animation based on 3D Technology}

At present, the new 3D animation creation of some colleges and universities has won good awards in various competitions at home and abroad, but the summary results of related art theories and technical processes are rare, which hinders the promotion and exchange of digital animation creation to some extent. In the $3 \mathrm{D}$ animation, the use of flying white is easy to produce sparks. Therefore, applying the animation style to the 3D animation does not completely copy all the elements, but requires the designer to make a flexible choice. This paper studies traditional animation classics from the perspective of cultural aesthetics, and summarizes the rules of its composition from the perspectives of modeling science and visual law. From the perspective of abstraction, intentionality, plasticity and contextual adaptation of 3D animation, this paper studies its formal linguistic features from the technical, hypothetical, role modeling, lens sense, space-time synthesis, and montage techniques of 3D animation. Three dimensional animation production has been completed after the role model, it is necessary to set action for the animation role. The design of the action should conform to the character's specific identity and personality, and reflect the role's emotional and psychological changes through the change of the action.

The curvature $\mathrm{Gg}$ of s vertex in each frame and the winding rate $\mathrm{Ga}$ are calculated as follows:

$$
\begin{gathered}
G_{g}(s)=\frac{K_{g}}{1+T_{d 0} s} \\
G_{a}(s)=\frac{K_{a}}{1+T_{a} s}
\end{gathered}
$$

Since these two factors have the same effect on the measurement of motion, the measure of motion 
here is as follows:

$$
Q\left(u_{i j}\right)=\sum_{i=1}^{n} \underset{1 \leq j \leq m}{\operatorname{ax}}\left\{g_{i j}(T)\right\}
$$

The error $\mathrm{C}$ of the $\mathrm{R}$ class is as follows:

$$
R_{n_{i}}^{C}=\log _{2}\left(1+\frac{p_{\text {mac }, n_{i}}\left\|\boldsymbol{h}_{\text {mac }, n_{i}}^{T} \boldsymbol{W}_{\text {mac }, n_{i}}\right\|_{2}^{2}}{\sigma^{2}}\right)
$$

Since the sum of the number of frames included in each class is the total number of frames $\mathrm{P}$, and the number of frames included in each class must be an integer, the selection of $\mathrm{C}$ cannot exceed the total number of frames, so the constraints are as follows:

$$
\operatorname{Cost}\left(P_{i}\right)=\sum_{e \in P_{i}} C(e)
$$

Suppose that the key frame $\mathrm{j}$ of the time domain clustering class $\mathrm{c}$ is spatially segmented and the number of partitioning blocks is $\mathrm{k}$, $\mathrm{k}$ should be selected such that the difference between the vertices contained in each block in the segmentation result is the smallest. That is, the objective function is:

$$
c\left(j_{1}, k\right)=c\left(j_{1}, k-1\right)+t_{j_{1} k}, k=2, \cdots, m
$$

The relationship between $\mathrm{k}, \mathrm{t}$ and $\mathrm{m}$ and the key length is shown in Table 1 and Figure 1.

Table 1 The relationship between $\mathrm{k}, \mathrm{t}$ and $\mathrm{m}$ and key length

\begin{tabular}{ccc}
\hline & Key length & Cycles \\
\hline AES-100 & 235 & 16 \\
AES-150 & 354 & 12 \\
AES-200 & 265 & 15 \\
\hline
\end{tabular}

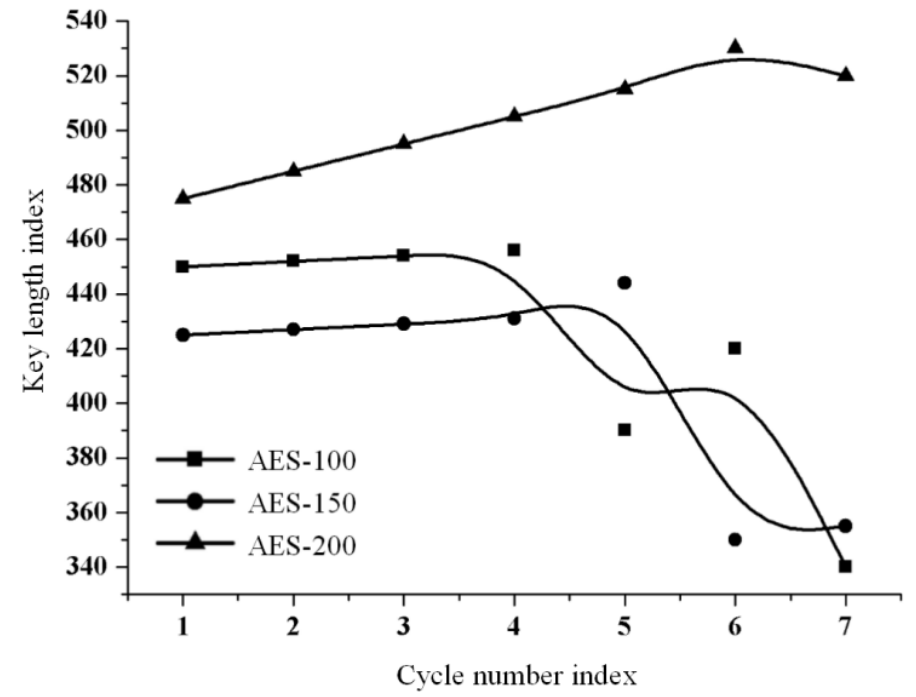

Figure 1 The relationship between $\mathrm{k}, \mathrm{t}$ and $\mathrm{m}$ and key length

The speed test simulation results of the AES-100 encryption algorithm are shown in Table 2 and Figure 2. 
Table 2 Speed test simulation results of AES-100 encryption algorithm

\begin{tabular}{cccccc}
\hline Frequency & 1 & 2 & 3 & 4 & 5 \\
\hline Time (s) & 50 & 59 & 55 & 52 & 56 \\
\hline
\end{tabular}

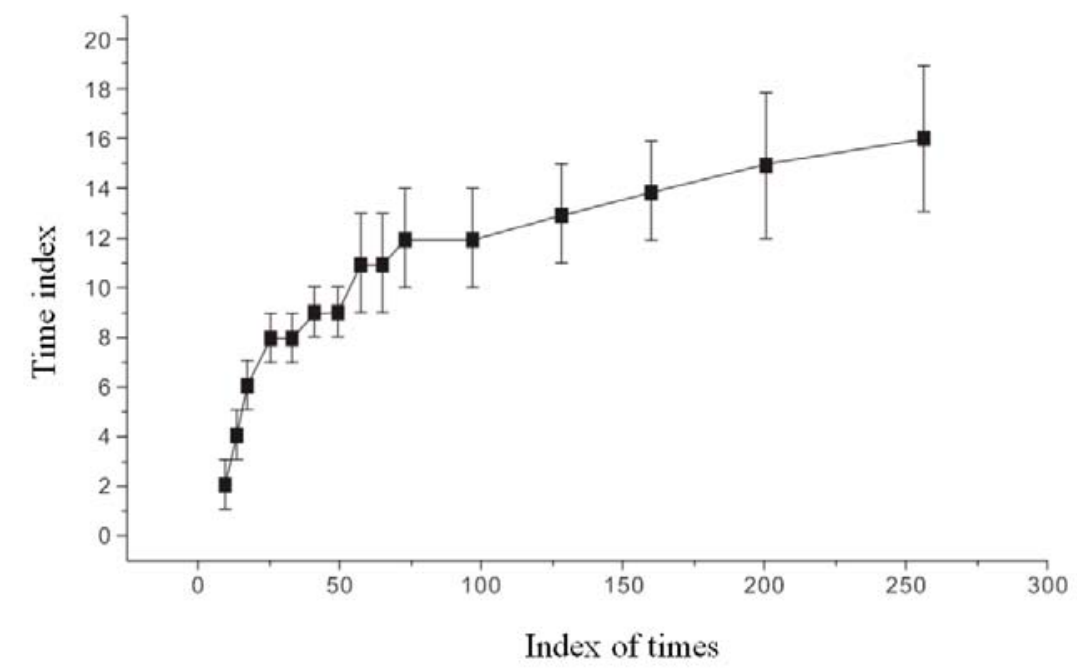

Figure 2 Speed test simulation results of AES-100 encryption algorithm

In this paper, five tests were performed to obtain the average value. The algorithm was executed 1000 times per test, and the operation time of the single algorithm was obtained. The results are shown in Table 3 and Figure 3 below.

Table 3 Wheel operation optimization algorithm speed test result

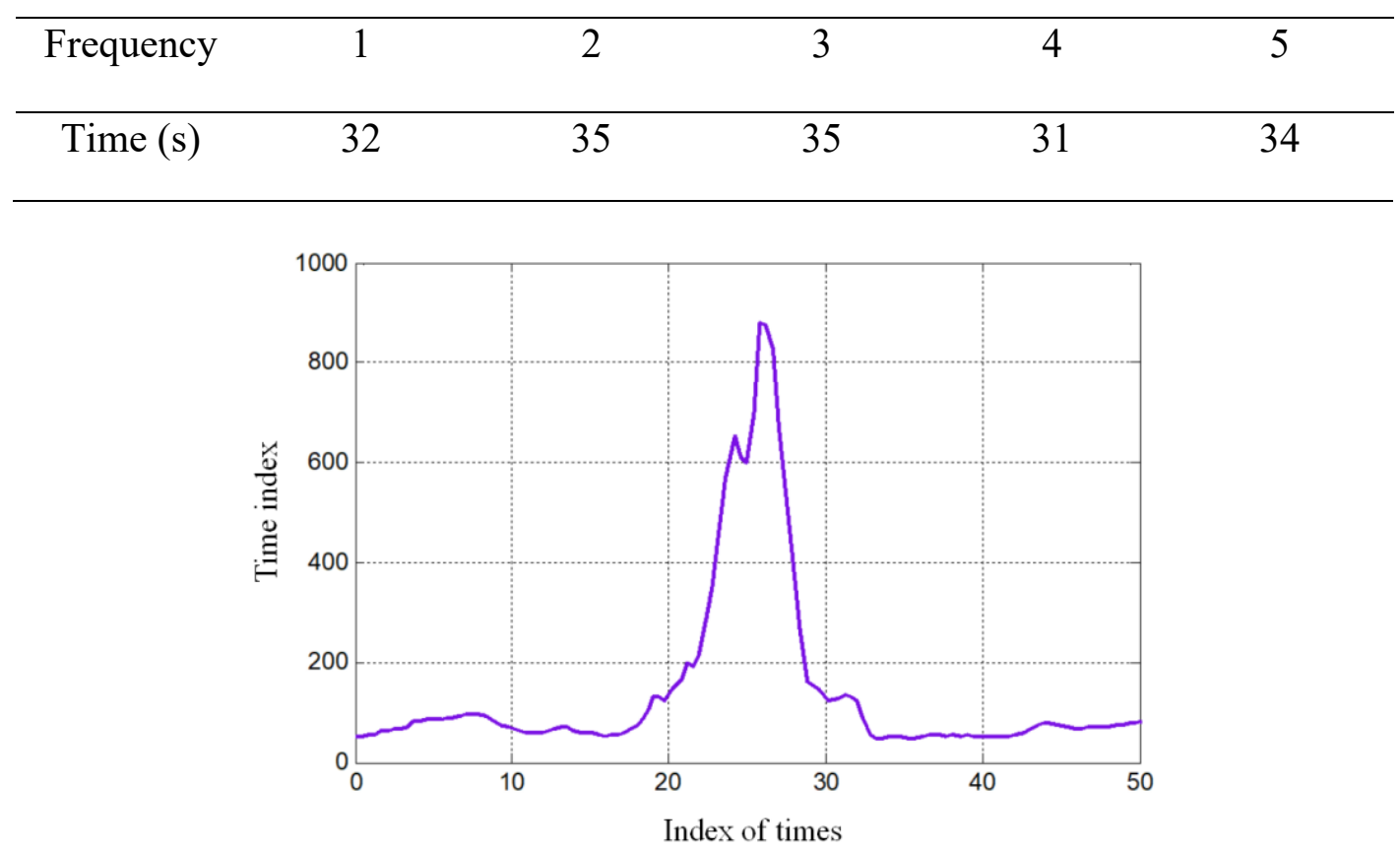

Figure 3 Wheel operation optimization algorithm speed test result

Five tests were used to obtain the average value. Each test performed the algorithm 1000 times, and the algorithm was run once. The results are shown in Table 4 and Figure 4 below. 
Table 4 Column confusion optimization algorithm speed test result

\begin{tabular}{cccccc}
\hline Frequency & 1 & 2 & 3 & 4 & 5 \\
\hline Time (s) & 48 & 65 & 65 & 32 & 81 \\
\hline
\end{tabular}

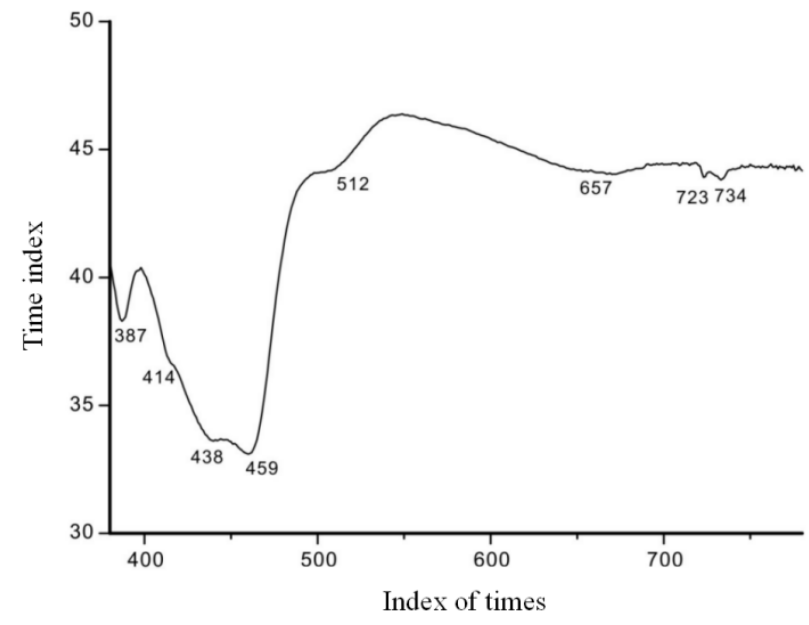

Figure 4 Column confusion optimization algorithm speed test result

The realization of 3D animation involves multi-disciplines such as Chinese painting, film and television animation, and computer application technology. Like 3D animation, 3D cartoons break through the level of art and reflect more highly in the high level of aesthetics. In the actual animation creation, we should also pay attention to the selection of music, the use of the lens and the composition of the picture, so that it can maintain the 3D animation and the free style of freehand, instead of blindly pursuing and imitating the performance of foreign film and television 3D animation. The symbols of 3D animation expressing things are introduced into the 3D animation software. By creating a 3D model, adjusting the animation, giving the material of the simulated pen and ink, processing the outline, and then rendering the sequence diagram in layers. Finally, the use of post-production to further proofread the color processing and special effects, control the animation shade, virtual reality changes, and strive to flexibly show the $3 \mathrm{D}$ virtual world, and ultimately form a $3 \mathrm{D}$ animation to achieve the basic technology and creative procedures and other new production mode.

\section{Conclusion}

3D digital technology is playing an increasingly important role in the production of film and television animation, animation art for the development of new vitality. This will be faster and more convenient than other methods and get more real 3D animation results. Computer simulation of 3D animation is a topic of practical significance, and it is a new inheritance and development of traditional Chinese painting art. In the new era, the development of animation in China also relies on the vitality brought by 3D digital technology. Only by combining the advantages of 3D digital technology in animation creation with the characteristics of animation art can we promote the rapid development of Chinese animation art. Fractal images with 3D animation style are used to make 3D animation rendering, and are used for 3D animation research, so that the application of fractal images is not only on the plane graphics, but also extended to the field of 3D animation, which is the biggest breakthrough of this research.

\section{References}

[1] Grant J , K Güçlü, Ç Ünal, et al. An Example for 3D Animated Character Design Process: The Lost City Antioch[J]. Procedia - Social and Behavioral Sciences, 2014, 122(2):65-71. 
[2] Lin, Dawei, Yang, et al. The Application of Digital Ink Painting in 3D Animation[J]. Applied Mechanics \& Materials, 2013, 311:322-327.

[3] Weng $\mathrm{T}$ S . Using the 3D digital orchid design program to cultivate digital talents[J]. Computer-Aided Design and Applications, 2016, 14(2):180-192.

[4] Shoufan A , Lu Z, Huss S A . A Web-Based Visualization and Animation Platform for Digital Logic Design[J]. IEEE Transactions on Learning Technologies, 2015, 8(2):225-239.

[5] Xu H , Li Y, Chen Y, et al. Interactive Material Design Using Model Reduction[J]. Acm Transactions on Graphics, 2015, 34(2):1-14.

[6] Leonardi V, Vidal V , Daniel M, et al. Multiple reconstruction and dynamic modeling of 3D digital objects using a morphing approach[J]. Visual Computer, 2015, 31(5):557-574.

[7] Ke Y, Zhijun S , Guo C, et al. Animation Design and Production of Kilometer Directional Drilling Technology and Equipment is [J]. Procedia Engineering, 2014, 73(73):305-310.

[8] Avramescu A M . Creating photo-realistic works in a 3D scene using layers styles to create an animation[J]. Journal of Clinical Investigation, 2015, 95(1):228-39.

[9] Hoyek N , Collet C, Rienzo F D, et al. Effectiveness of Three-Dimensional Digital Animation in Teaching Human Anatomy in an Authentic Classroom Context[J]. Anatomical Sciences Education, 2015, 7(6):430-437.

[10] Shoufan A, Lu Z, Huss S A . A Web-Based Visualization and Animation Platform for Digital Logic Design[J]. IEEE Transactions on Learning Technologies, 2015, 8(2):225-239. 